\title{
Detailed Heat Transfer Distribution on the Endwall of a Trapezoidal Duct with an In-Line Pin Array
}

\author{
JENN-JIANG HWANG* and CHAU-CHING LU \\ Department of Mechanical Engineering, Chung-Hua University, Hsinchu, Taiwan 300, ROC
}

\begin{abstract}
This study presents the measurements of detailed endwall heat transfer and pressure drop in a pin-finned trapezoidal duct. The trapezoidal duct is inserted with an in-line pin array of five rows and five columns, with the same spacings between the pins in streamwise and spanwise directions of $S_{x} / d=S_{y} / d=2.5$. The effects of the lateral-flow ejection $(0 \leqq \varepsilon \leqq 1.0)$ and flow Reynolds number $(6000 \leqq R e \leqq 40000)$ are examined. Transient liquid crystal technique is employed to measure the detailed heat transfer on the endwall of a pinfinned trapezoidal duct. Results indicate that the pin-finned trapezoidal duct of a lateral-flow rate about $\varepsilon=0.3$ has a local minimum endwall-averaged Nusselt number. In addition, the trapezoidal duct of lateral outlet flow only $(\varepsilon=1.0)$ has a highest endwall heat transfer as well as pressure drop. Finally, the correlation of the endwall-averaged heat transfer for the pin-finned trapezoidal duct is developed by taking account of the lateral-flow rate and the flow Reynolds number.
\end{abstract}

Keywords: Pin fin; Trapezoidal duct; Lateral-flow ejection; Transient liquid crystal technique

Augmentation of heat transfer inside airfoil internal channels is an important issue for the gas turbine industry. As turbine inlet temperatures are increased, there is a greater need for more efficient cooling. Many cooling strategies have been developed over the years. The most familiar internal-cooling method as shown in Figure 1 is augmented forced convection in various-shaped channels by using rib turbulators and/or pin fins. This study focuses on the internal cooling near the trailing edge of a turbine blade, in which pin fins spanning between the suction and

Received 15 December 1999; In final form 21 April 2000.

* Corresponding author. Tel.: 886-35-374281 Ext. 8334, Fax: 886-35373771, e-mail: jjhwang@chu.edu.tw pressure surfaces to promote turbulence, and thus internal heat transfer.

Some relevant studies about pin fin heat transfer are briefly surveyed below. VanFossen (1982) measured the overall heat transfer coefficients in rectangular ducts with staggered arrays of short pin fins $(0.5<l / d<2.0)$. All arrays had four rows of pins in the streamwise direction. Heat transfer rates were averaged over the four-row array. It was found that the overall heat transfer coefficients for short pins were lower than those for long pin fins $(l / d=8.0)$. Metzger et al. (1982) studied experimentally the local heat transfer variation in rectangular ducts with a staggered pin array for $S_{x} / d=1.5$, and $S_{y} / d=2.5$, and $l / d=1.0$. Results showed that heat transfer increased in the first few rows, reached a peak value and then slowly decreased to a fully developed value. Later, Metzger et al. (1984) further studied the effects of using flattened pins and of varying the orientation of the pin fin array with respect to the main flow direction on the heat transfer and pressure drops in pin finned channels. They observed that, by varying the orientation of the pin-fin array, it was possible to increase the heat transfer and, at the same time, reduce the pressure drop. They also found that the use of flattened pins increased the heat transfer slightly but doubled the pressure loss. Lau et al. (1987) conducted a naphthalenesublimation experiment to determine the distributions of the local endwall heat transfer coefficient in rectangular channels with in-line and staggered pin-fin arrays. The effects of varying the Reynolds number and the pin configuration on the local endwall heat transfer coefficient distribution were examined. Overall, and row-averaged Nusselt numbers were found to be in a good agreement with those in Metzger et al. (1982). Lau et al. (1989) further measured the overall heat transfer and friction factor in pin-finned rectangular channels with lateral ejection. It was shown that the overall heat transfer for a pin-finned rectangular channel with lateral ejection holes was lower than that for rectangular channel with no ejection holes. Chyu (1990) used a mass transfer sublimating system to 


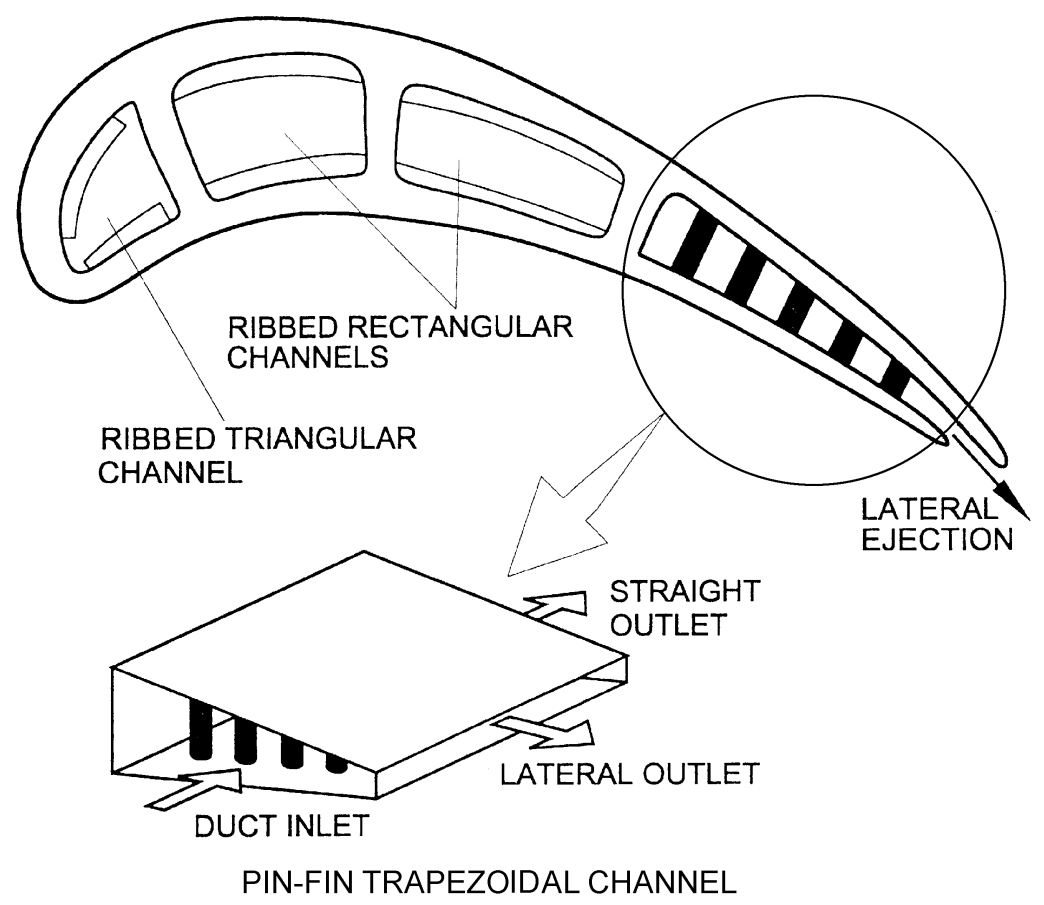

FIGURE 1 Typical modern internally cooled turbine blade and the pin-finned trapezoidal duct.

evaluate the effects of fillets at the cylinder-endwall junction and array geometry on the endwall heat transfer in rectangular ducts. Then, Chyu et al. (1998) examined the pin-shape effect on the heat/mass transfer characteristics in a narrow rectangular channel. The staggered cube array was recommended since it produced a significant heat transfer enhancement and a moderate pressure penalty. Chyu et al. (1999) further conducted experiments to compare the contribution of heat transfer enhancement by the endwall and that by the pins in a pin-fin rectangular duct. Results revealed that the pin has about 10-20 percent higher heat transfer than the endwall. However, such a difference in heat transfer coefficient imposed very insignificant influence on the overall array-averaged heat transfer since the wetted area of the uncovered endwalls was much greater than that of the pins. All aforementioned studies are for flow through rectangular channels with a uniform pin length. However, as shown in Figure 1, the blade profile has a small wedge angle near the trailing-edge region that results in a narrow trapezoidal cooling cavity. In this circumstance, the pin pins spanning between two principal walls of the trapezoidal duct should be of different in length. A more realistic geometry of the pinfinned trapezoidal cooling cavity in a typical turbine blade has not been studied until Hwang et al. (1999), in which the log-mean heat transfer and overall pressure drop in a trapezoidal pin-finned duct are measured. However, the local heat transfer characteristics, which are highly desired in the turbine-blade cooling design, were not determined.

In this study, we continue our previous work (Hwang et al., 1999) to measure the detailed heat transfer coefficient on the endwall of a pin-finned trapezoidal duct by using a transient liquid-crystal technique (Hwang and Chen, 1999). Therefore, the effects of lateral-flow injection and the flow Reynolds number on the endwall heat transfer and pressure drop in a trapezoidal duct with an in-line pin array are examined. In addition, an empirical correlation for the endwall heat transfer in a pin-finned trapezoidal duct is developed by considering the effects of the lateral-flow rate and the flow Reynolds number. The detailed distributions of heat transfer coefficient provided by the present work could afford a better understanding of the endwall heat transfer enhancement by pin fins in a trapezoidal duct with lateral-flow injection. They could also provide a reference of computational-fluid-dynamic-based studies relating to the pin-fin-duct heat transfer.

\section{EXPERIMENTAL PROGRAM}

\section{Apparatus}

A schematic layout of the present experimental apparatus is shown in Figure 2. Air from the laboratory room is sucked into the flow circuit by a 15-hp centrifugal blower. 


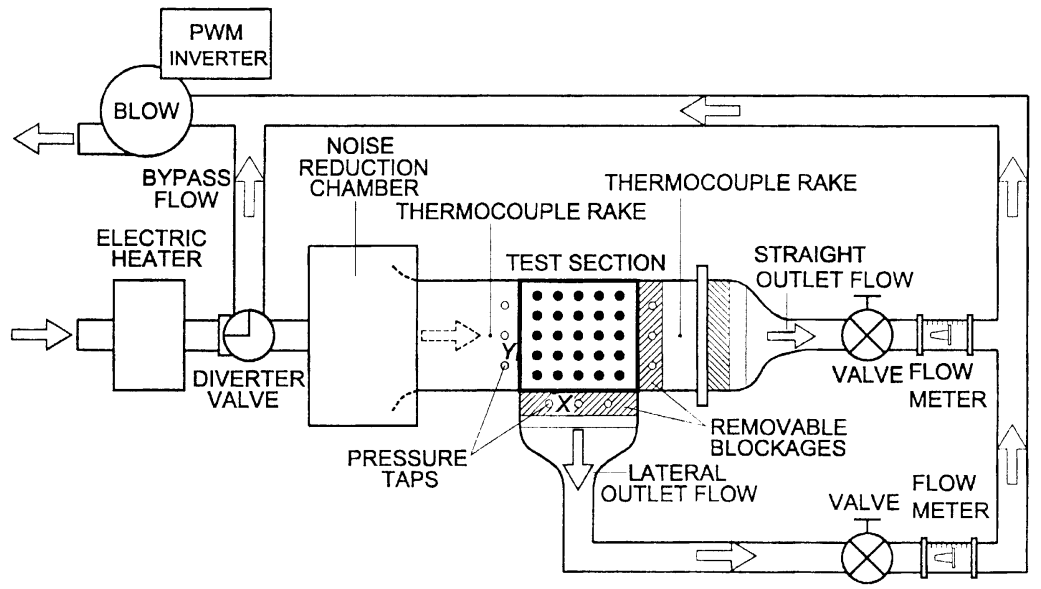

FIGURE 2 Sketch of the flow loop and experimental apparatus.

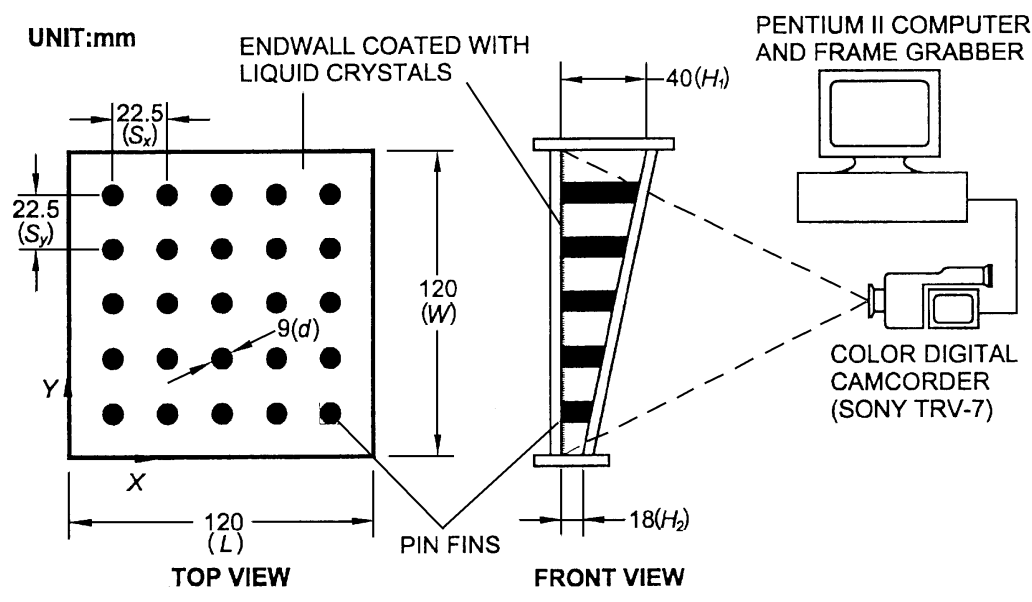

FIGURE 3 Dimensions and coordinate system of the test section.

Before entering the test section, the air is ducted into an electric heater to be heated to a required temperature, subsequently traverses a noise-reduction chamber, and an entrance section. Finally, the air exits from the straight and/or lateral outlets. A flow meter together with a valve situated at each outlet measures and controls the volume flow rate of the air. As shown in Figure 3, the trapezoidalshaped test section and the pins are made of Plexiglas ${ }^{\circledR}$. The bottom endwall of a square area of $120 \mathrm{~mm}$ by $120 \mathrm{~mm}$ ( $L$ by $W$ ) is sprayed with liquid crystals, representing the heat transfer active surface. Twenty-five pins spanning the distance between two principal duct walls are arranged by an in-line fashion. The diameter $(d)$ of the circular pin is $9 \mathrm{~mm}$. All pins are screwed in place from the bottom endwall, and thus stand vertically on the endwall. They have different lengths from $l / d=2.5$ to 4.6 , depending on the location within the trapezoidal duct. The pin spacings along the longitude and transverse directions are the same, i.e., $S_{x}=S_{y}=22.5 \mathrm{~mm}$. The heights of the long $\left(H_{1}\right)$ and short $\left(H_{2}\right)$ side walls are $40.0 \mathrm{~mm}$ and $18.0 \mathrm{~mm}$, respectively, forming a wedge angle about $10.4 \mathrm{deg}$. As shown in Figure 2, two thermocouple rakes (each has five beads) are located at the test-section entrance and exit (straight or lateral), respectively, to measure the mainstream temperatures. A real-time hybrid recorder (YOKOGAWA, AR 1100A) records the time-dependent mainstream temperatures. In addition, nine pressure taps are installed at the entrance and two exits of the test section (each has three taps) for the static-pressure measurement. They are connected to a transmitter (MODUS) to display the pressuredrop signals.

The image-processing system includes a digital color camcorder (SONY DCR-TRV7), a frame grabber card, and a Pentium II personal computer. The camcorder is focused on the liquid-crystal-coated surfaces to view and record their color change during the transient test. The frame grabber interface is programmed to analyze the color change using an image-processing software. The software 
analyzes the picture frame-by-frame and simultaneously records the time lapse of the liquid crystals from colorless to green during the transient test.

\section{Experimental Procedure}

The test section is assembled after spraying the liquid crystals (Hallcrest, BW/R38C5W/C17-10) uniformly on the endwall surface. The camcorder is set up and focused on the endwall surface. Each test run is thermal transient, initiated by suddenly exposing the hot air to the test section, which results in a color change of the surface coatings. The liquid crystals are colorless at room temperature. It then changes to red, green, blue and finally colorless again during the heating process. The temperatures for color changed to red, green and blue are $38.2^{\circ} \mathrm{C}, 39.0^{\circ} \mathrm{C}$ and $43.5^{\circ} \mathrm{C}$, respectively (Hwang and Chen, 1999). Before the test run, the hot air bypasses the test section so that the endwall remains at the laboratory ambient temperature. The valve keeps in the diverted position until a required mainstream temperature (typically about $60-70^{\circ} \mathrm{C}$ ) has been achieved in the diversion of the flow loop. Then, the valve turns to route the hot air into the test section and, simultaneously, the recorder is switched on to record the mainstream temperature history. The image processing system records the transition time for the color change to green, and transfers the data into a matrix of time of the color change over the entire surface. The time and temperature data are entered into a computer program to obtain the local heat transfer coefficient.

\section{Heat Transfer Theory}

The local heat transfer coefficient over the test surface can be obtained by assuming one-dimensional transient conduction over a semi-infinite solid. The one-dimensional transient conduction, the initial condition, and boundary conditions on the liquid crystal coated surface are

$$
\begin{gathered}
k \frac{\partial^{2} T}{\partial Z^{2}}=\rho c_{p} \frac{\partial T}{\partial t} \\
\text { as } t=0, T=T_{i} ; \quad \text { as } t>0, k \frac{\partial T}{\partial Z}=h\left(T_{w}-T_{m}\right) \\
\text { at } z=0 ; T=T_{i}, \text { as } z \rightarrow \infty
\end{gathered}
$$

The surface temperature response to the equation above is shown as:

$$
\frac{T_{w}-T_{i}}{T_{m}-T_{i}}=1-\exp \left(\frac{h^{2} \alpha t}{k^{2}}\right) \cdot \operatorname{erfc}\left(\frac{h \sqrt{\alpha t}}{k}\right)
$$

The heat transfer coefficient $h$ can be calculated from the above equation, by knowing the wall temperature $\left(T_{w}\right)$, the initial surface temperature $\left(T_{i}\right)$, the oncoming mainstream temperature $\left(T_{m}\right)$, and the corresponding time $(t)$ required to change the coated-surface color to green at any location. The time required for the color change in a typical run is about 15 to 90 seconds depending on the location, mainstream temperature, and throughflow rate. This testing time is so short that the heat flow can hardly penetrate the depth of the acrylic. Therefore, the assumption of the semiinfinite solid on the test surface is valid. Noteworthy that in the region where the heat transfer coefficient varies significantly in spatiality, the heat transfer coefficient measured may be somewhat averaged by the axial conduction in the Plexiglas ${ }^{\circledR}$ plate (i.e., two- or three-dimensional effect). For checking this effect, two thermocouples are cemented into small holes drilled into the Plexiglas ${ }^{\circledR}$ plate approximately $1.0-\mathrm{mm}$ in depth to measure the time-dependent axial conduction. The locations of these two thermocouples are behind the pin and ahead of the next pin, respectively, where the heat transfer is expected to be highly localized. The results show that the maximum axial conduction is less than $5 \%$ of the convection heat transfer from the fluid to the surface in the test duration.

Since the mainstream temperature is time-dependent, the solution in Eq. [2] should be modified. First, the mainstream temperature history is simulated as a series of time step changes. Then, the time step changes of the mainstream temperature are included in the solution for the heat transfer coefficient using Duhamel's superposition theorem. The solution for the heat transfer coefficient at every location is therefore represented as

$$
\begin{aligned}
T_{w}-T_{i}=\sum_{j=1}^{n}\left\{1-\exp \left[\frac{h^{2} \alpha\left(t-\tau_{j}\right)}{k^{2}}\right] \times\right. \\
\left.\operatorname{erfc}\left[\frac{h \sqrt{\alpha\left(t-\tau_{j}\right)}}{k}\right]\right\}\left[\Delta T_{m(j, j-1)}\right]
\end{aligned}
$$

where $\Delta T_{m(j, j-1)}$ and $\tau_{j}$ are the temperature and time step changes obtained from the recorder output.

\section{Data Reduction}

The nondimensional heat transfer coefficient on the endwall of the trapezoidal duct is represented by the Nussult number as

$$
N u=h D e / k_{f}
$$

The Reynolds number used herein is based on the mean throughflow velocity at the duct entrance and the equivalent hydraulic diameter of the trapezoidal duct, i.e.,

$$
R e=G \cdot D e / \mu
$$


TABLE I Typical nondimensional interval for the relevant variables

\begin{tabular}{lc}
\hline Variables & Uncertainty \\
\hline Air density, $\rho$ & $\pm 1.6 \%$ \\
Specific heat of air, $c_{p}$ & $\pm 3.0 \%$ \\
Kinematic viscosity of air, $\nu$ & $\pm 2.9 \%$ \\
Wall thermal diffusivity and conductivity, $\alpha$ and $k$ & $\pm 3.0 \%$ \\
Equivalent duct hydraulic diameter, $D_{e}$ & $\pm 0.5 \%$ \\
Air mass flux, $G$ & $\pm 5.4 \%$ \\
Main stream temperature, $T_{m}$ & $\pm 3.0 \%$ \\
Pressure difference, $\Delta P$ & $\pm 5.1 \%$ \\
\hline
\end{tabular}

Note that the above reductions of $N u$ and $R e$ are similar to those in VanFossen (1982), but are different from those in Metzger et al. (1982), in which Nusselt number and the Reynolds number are based on the pin diameter. This is because Metzger et al. (1982) were devoted to pin-fin heat transfer, while the endwall-heat-transfer enhancement due to the pin fins in a trapezoidal duct is interested in the present study and VanFossen (1982).

The pumping power required to drive a fixed volumetric flow rate $\dot{V}$ in the trapezoidal duct with both straight and lateral outlets can be written as

$$
\Delta P \dot{V}=\Delta P_{1} \dot{V}_{1}+\Delta P_{2} \dot{V}_{2}
$$

where $\dot{V}_{1}$ and $\dot{V}_{2}$ are the volumetric flow rates, and $\Delta P_{1}$ and $\Delta P_{2}$ the measured pressure drops for flow through the straight exit and the lateral exit, respectively. If the density of the flowing air does not vary significantly in the teat section, the pressure drop across the finite-length duct of trapezoidal cross section with both straight and lateral outlets, can be made dimensionless as follows

$$
E u=2 \Delta P /\left(G^{2} / \rho\right)
$$

The pressure-drop coefficient obtained is based on adiabatic conditions (i.e., test with ambient-temperature mainstream).

By using the estimation method of Kline and McClintock (1953), the maximum uncertainties of the investigated nondimensional parameters are as follows: $R e$, $6.4 \% ; N u, 8.5 \%$ and $E u, 7.7 \%$. The individual contributions to the uncertainties of the nondimensional parameters for each of the measured physical properties are summarized in Table I.

\section{RESULTS AND DISCUSSION}

\section{Detailed Heat Transfer Coefficient Distributions}

Typical examples showing the effects of lateral-flow rate on the detailed Nusselt number distributions on the endwall surfaces of a trapezoidal duct with pin fins are given in Figure 4. The trapezoidal duct is inserted with an in-line pin array at a fixed Reynolds number of $R e=40000$. The lateral-flow rate varies from $\varepsilon=0$ to 1.0 .

For the duct of a straight outlet flow only (Figure 4(a), $\varepsilon=0$ ), the local heat transfer coefficient distributions are slightly asymmetric due to the difference in the sidewall effects. In addition, high and low heat transfer coefficients are observed ahead of and behind each pin, respectively. When the lateral exit is open with $\varepsilon=0.2$ (Figure 4(b)), only a small portion of fluids turns laterally and most fluids still traverses the trapezoidal duct and exits through the straight exit. Therefore, the pattern of heat transfer distribution on a large portion of endwall shown in Figure 4(b) is not changed too much as compared to Figure 4(a). The notable differences are a slightly reduction in $N u$ value and the deflection of wake shedding behind the pins adjacent to the lateral exit for Figure 4(b). It is seen that the wake shedding behind the pins adjacent to the lateral exit, except for the last row, is slightly deflected toward the lateral exit by the lateral flow. Interestedly, the pin around the corner formed by tow opens of the duct (i.e., the last-row pin adjacent to the lateral exit) has a shedding wake directed from the lateral exit toward the straight exit. This means that there are some fluids enter the duct from the lateral opening and exit from the straight opening. Such a complex flow transportation will be illustrated later in Figure 5. As the lateral flow rate increases further (Figures 4(c) (d) and (e)), the deflection of wake shedding behind the pins becomes significant, and the heat transfer in the region near the lateral exit has been enhanced by increasing $\varepsilon$. Meanwhile, the heat transfer coefficient near the longer sidewall is evidently degraded. The former is attributed to the effect of the accelerating flow through the convergent lateral exit and, partly, the flow turning effect. The latter is because of the less in forced convection along the straight $(X)$ direction of the trapezoidal duct. In contrast to the results of small lateral flow injection shown in Figure 4(b), the direction of the wake shedding by the pin around the corner formed by tow openings is from the straight exit to the lateral exit for the high lateral injection of $\varepsilon=0.8$, indicating that the flow across this pin is from the straight open to the lateral open. When the straight exit is blocked (Figure 4(f), $\varepsilon=1.0$ ), the total main flow has to turn laterally, and thus enhances the most heat transfer near the lateral exit. However, due to the flow recirculation, a heat transfer deterioration is observed around the remote corner formed by the longer sidewall and the blocked straight exit.

From the heat transfer traces above, the flow direction across the trapezoidal duct under various values of $\varepsilon$, which strongly affects the local heat transfer distribution on the endwall surfaces, can be sketched in Figure 5. For $0<\varepsilon \leq 0.4$, due to a strong vacuum at the straight exit, the total straight outlet flow is induced not only from the 

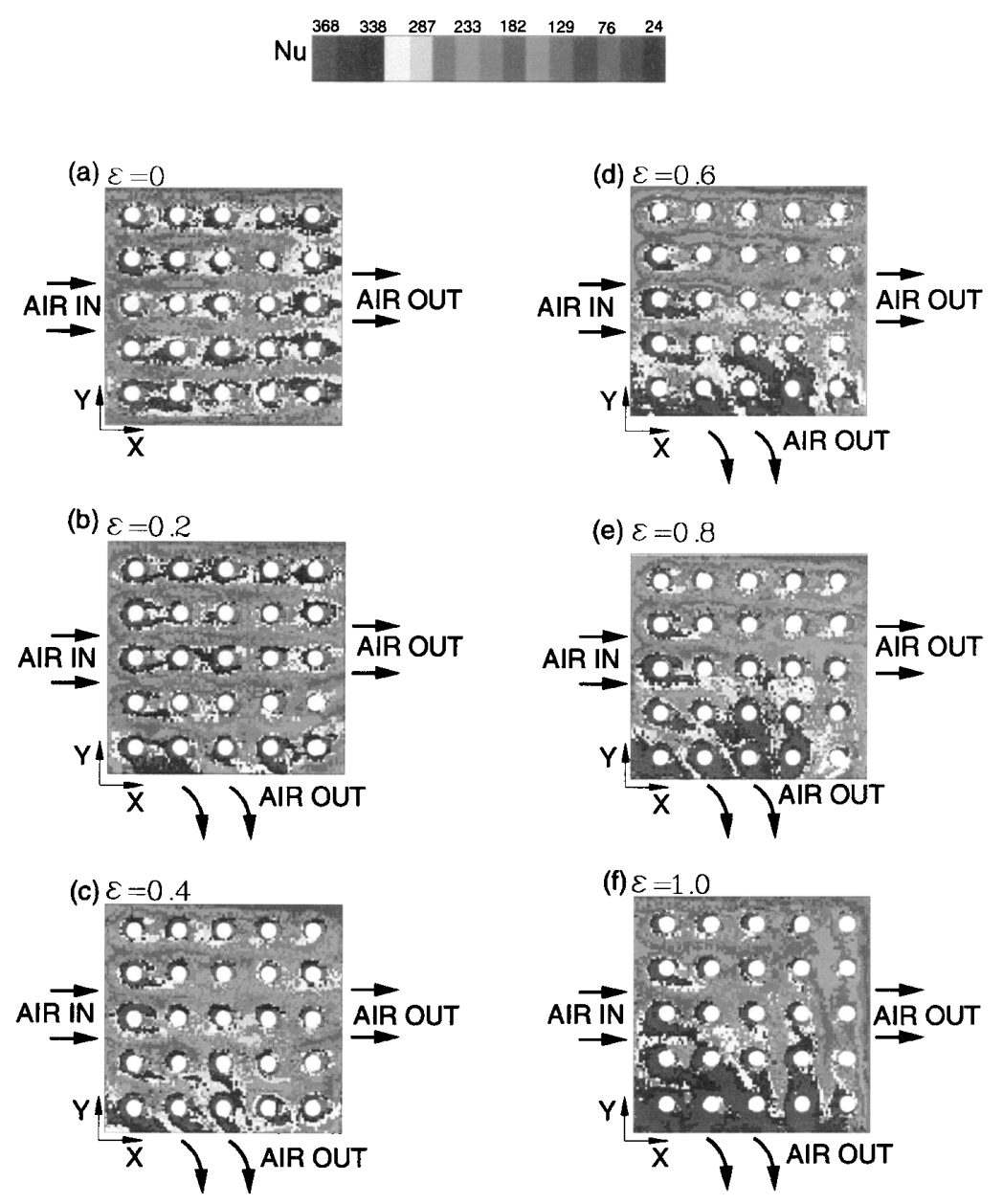

FIGURE 4 Effect of the lateral-flow rate on the detailed heat transfer coefficient distribution on the endwall of the trapezoidal duct at $R e=40,000$ (See Colour Plate at back of issue.).

duct entrance but also from the lateral opening (Figure 5(a)). For the duct of $0.6 \leq \varepsilon<1.0$ (Figure 5(c)), contrarily, the fluids exiting from the lateral exit are provided by the duct entrance as well as the straight open. As for $0.4<\varepsilon<$ 0.6 , the straight and lateral outflows are even almost (Figure 5(b)) due to the vacuum balance in the two exits.

\section{Endwall Averaged Heat Transfer}

Figure 6 shows the effect of the lateral-flow rate on the endwall-averaged heat transfer in a trapezoidal duct at $R e=40,000$. The symbols are actual experiments and the solid line passing through these symbols is a curve-fitting result. As given in this figure, the endwall-averaged Nusselt number starts a decrease from $\varepsilon=0$, reaches a local minimum at about $\varepsilon=0.3-0.4$, and then increases with increasing $\varepsilon$. The first decrease is because the apparent cross-sectional area for the throughflow becomes large when the lateral exit is open. An increase in the apparent cross section area reduces the average throughflow velocity; hence endwall-averaged heat transfer. Further increasing the lateral-flow rate augments the convective heat transfer by accelerating fluid through the convergent lateral exit and by enhancing the flow turning effect. The more the lateral flow is, the stronger the fluid acceleration becomes. This is the reason why the endwall-averaged heat transfer increases with the increase in the lateral-flow rate at high lateral-flow conditions. Noteworthy that the previous results by Lau et al. (1989) showed that the overall heat transfer is decreased monotonically with increasing the lateral-flow rate from $\varepsilon=0$ to 1.0 in the pin-finned rectangular duct. The disagreement in the $\varepsilon$-dependence of the overall heat transfer between the present and previous results may be due to the difference in the cross section of the test duct investigated.

The dependence of the endwall-averaged Nusselt number on the Reynolds number and the lateral-flow rate can be correlated by the equation of the form

$$
\overline{N u}=0.226 \operatorname{Re}^{0.649}\left(1-0.21 \varepsilon+0.32 \varepsilon^{2}\right)
$$




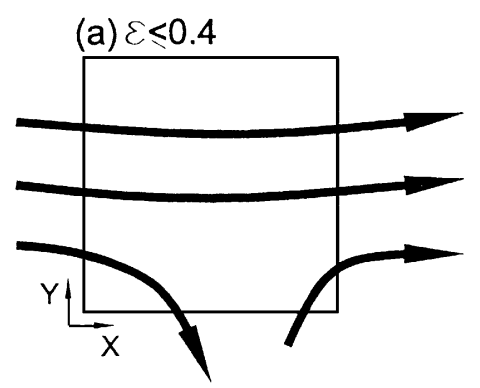

(b) $0.4<\varepsilon<0.6$

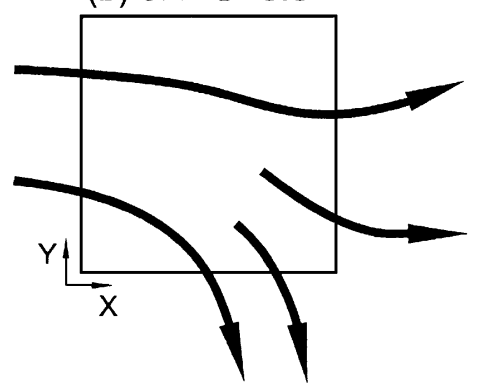

(c) $\varepsilon \geqslant 0.6$

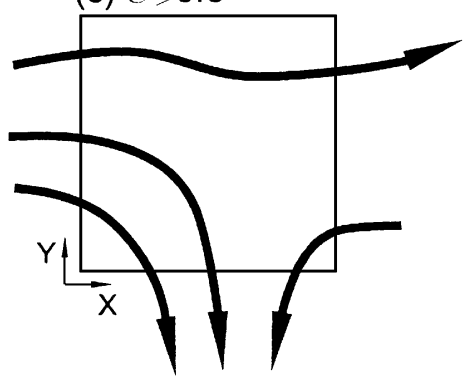

FIGURE 5 Relation of the lateral-flow rate and the main flow direction in the trapezoidal duct.

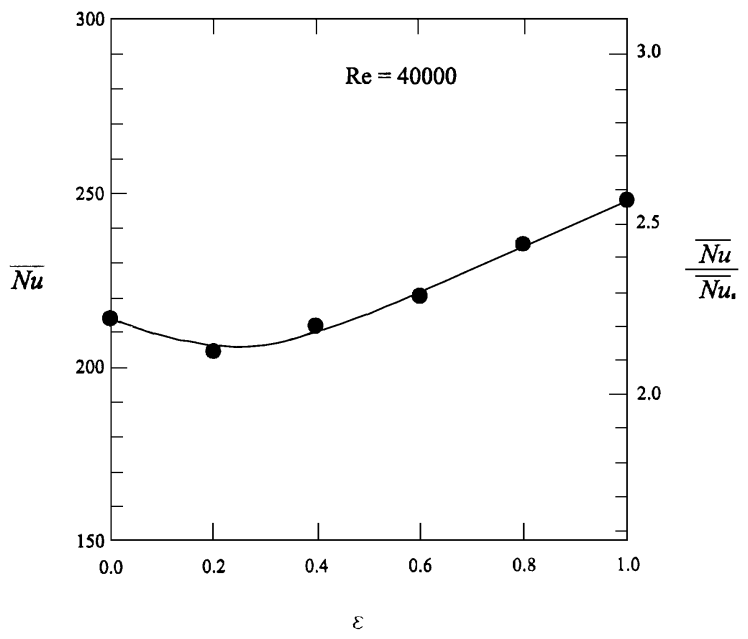

FIGURE 6 Effect of the lateral-flow rate on the endwall-averaged Nusselt number at $R e=40,000$.

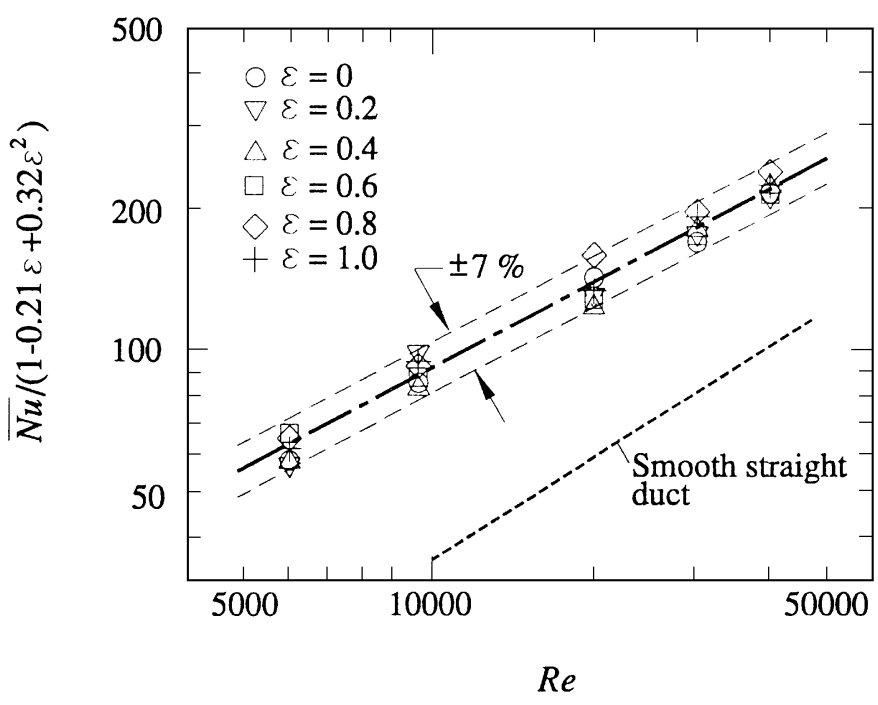

FIGURE 7 Endwall-averaged Nusselt number as a function of the Reynolds number.

The maximum deviations between the equations above and the experimental data are less than \pm 7 percent. The combined effects of lateral-flow rate and Reynolds number on the endwall-averaged heat transfer of the trapezoidal duct with an array of various-shaped pins are shown in Figure 7. For simplicity, the effect of lateral-flow rate is expressed explicitly in the ordinate of the figure. As shown in Figure 7, the data for various $\varepsilon$ gather closely at a fixed Reynolds number, meaning that the dependence of $\varepsilon$ on the $\overline{N u}$ in Eq. [8] is appropriate. From Figure 7, in general, the endwallaveraged Nusselt number of the trapezoidal pin-finned duct increases with increasing the Reynolds number. In comparison of the smooth duct results of the straight flow (Dittus and Boelter, 1930), the enhancement in the endwall averaged heat transfer is about $130-210 \%$ for various lateral flow rates.

\section{Pressure Drops}

The results of the pressure-drop experiments are presented in Figure 8. In this figure, the Euler number, defined in Eq. [7], is plotted as a function of the flow Reynolds number for various lateral-flow rates. For all lateral-flow rates, the Euler number depends mildly on the flow Reynolds number over the range of Reynolds number studied.

As for the effect of lateral-flow rate, similar to the heat transfer results, the Euler number is first decreased and then increased with increasing $\varepsilon$. The minimum $E u$ occurs at about $\varepsilon=0.4$. Increasing the lateral-flow rate from $\varepsilon=0$ to 0.4 has two counteracting effects that influence the overall pressure drop across the trapezoidal duct. The first is the reduction in the volumetric flow rate or the air in the duct due to an increase in the apparent exit area, which reduces the pressure drop across the trapezoidal duct. 


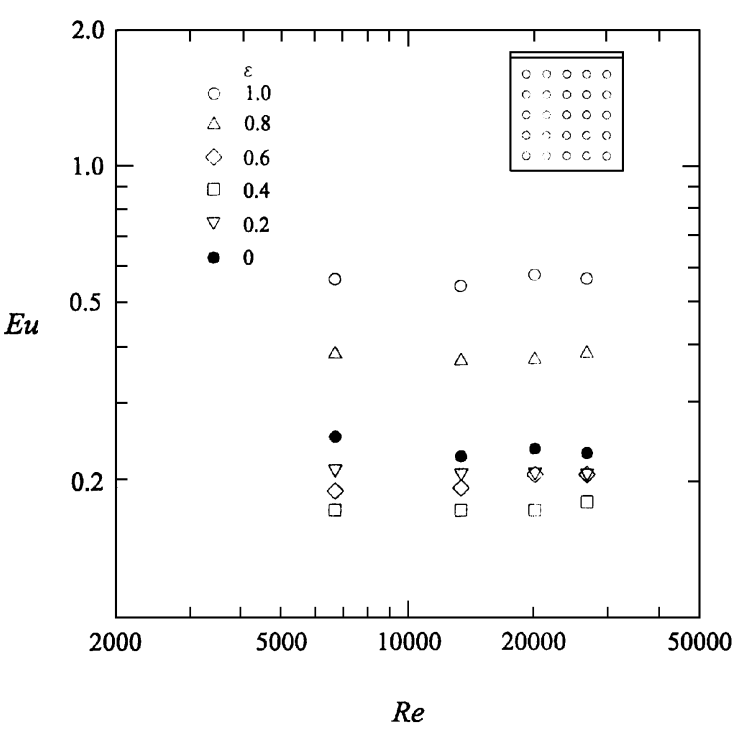

FIGURE 8 Reynolds-number dependence of Euler number for the pinfinned trapezoidal duct under various lateral flow rates.

The second effect is an enhancement in the flow turning effect, which increases the pressure drop. Obviously, the former effect is more significant than the latter effect for $\varepsilon \leq 0.4$. As $\varepsilon$ increases further, the flow-turning effect is graduately crucial. After $\varepsilon \geq 0.8$, the $E u$ is higher that of $\varepsilon=0$ (solid circles), meaning that the flow-turning effect has overcame the area-increment effect. At $\varepsilon=1.0$, the Euler number has a maximum value and is about $100-130$ percent higher than that of straight outlet flow. The turning of the flow through $90 \mathrm{deg}$ angle and the recirculation of trapped air at the corner between the longer sidewall and the blocked straight exit for $\varepsilon=1.0$ cause a significant pressure drop in the pin-finned channel.

\section{CONCLUDING REMARKS}

Measurements of endwall heat transfer and pressure drop in a trapezoidal duct with an in-line pin-fin array, simulating the trailing edge cooling cavity of a turbine blade, have been conducted. Lateral flow rate and flow Reynolds number are of the ranges $0 \leqq \varepsilon \leqq 1.0$ and $6000 \leqq R e \leqq 40000$, respectively. New information of detailed heat transfer distributions on the endwall surfaces of a pin-finned trapezoidal channel with various lateral flow rates has been provided in this study. Increasing $\varepsilon$ enhances the local heat transfer in the region near the lateral exit but degrades the local heat transfer in the region adjacent the longer sidewall. The former is attributed to the effect of the accelerating flow through the convergent lateral exit together with the flow-turning effect. The latter is because of the less in forced convection along the straight $(X)$ direction of the trapezoidal duct. As for the endwallaveraged heat transfer, it decreases with increasing $\varepsilon$ from

zero to a small lateral-flow rate (say, $\varepsilon=0.3-0.4$ ) due to an increase in the duct throughflow area, which reduces the forced convection in the trapezoidal duct. For $\varepsilon \geq 0.4$, however, the endwall-averaged heat transfer increases with increasing $\varepsilon$ due to the significance of flow-turning effect. Consequently, a local minimum in $\overline{N u}$ occurs at about $\varepsilon=0.3$ for the pin-finned trapezoidal duct. Similarly, as the lateral-flow rate increases from $\varepsilon=0$ to 1.0 , the pressure drop across the trapezoidal duct decreases first, reached a local minimum at about $\varepsilon=0.4$ and then increases to a maximum at $\varepsilon=1.0$. A new correlation for endwallaveraged heat transfer in the trapezoidal duct with an array of the pin fins is developed in terms of the lateral flow rate and the flow Reynolds number for the design purpose.

\section{NOMENCLATURE}

$c_{p}$

$D_{e}$

$d$

$\mathrm{Eu}$

$G$

$H_{1}$

$\mathrm{H}_{2}$

$h$

$k$

$k_{f}$

$L$

$l$

$\overline{N u}$

$\overline{N u}_{s}$

$P$

$\operatorname{Pr}$

$\Delta P$

$R e$

$S_{x}$

$S_{y}$

$T_{i}$

$T_{m}$

$T_{w}$

$t$

$U$

$\dot{V}$

W specific heat at constant pressure

equivalent hydraulic diameter at the test duct inlet

pin characteristic length, i.e., diameter of the circular pin

Euler number, Eq. [7]

total mass flux

height of the longer side wall of the trapezoidal duct, see Figure 3

height of the short side wall of the trapezoidal duct, see Figure 3

heat transfer coefficient

thermal conductivity of the endwall material

air thermal conductivity

trapezoidal duct length along streamwise direction, see Figure 3

$l$ fin length (or height)

endwall-averaged Nusselt number of the pin finned channel, $h D_{e} / k_{f}$

fully developed Nusselt number for a smooth duct, $\overline{N u}_{s}=0.023 \operatorname{Pr}^{0.4} R e^{0.8}$

pressure

Prandtl number

pressure drop across the test section entrance and exit

Reynolds number, $U D_{e} / \nu$

streamwise spacing between pins

spanwise spacing between the nearby pins

initial wall temperature

mainstream temperature

wall temperature

time

bulk mean velocity of air at the duct inlet

volumetric flow rate of air

spanwise distance of the heated plate, see Figure 3

$X, Y, Z$ coordinates as defined in Figure 3 


\section{Greek Symbols}

$\alpha \quad$ thermal diffusivity of the endwall material

$\varepsilon \quad$ ratio of the lateral-to-total flow rate

$\rho \quad$ air density

$\mu \quad$ viscosity of air

$\tau_{j} \quad$ time step

\section{Subscripts}

$\begin{array}{ll}i & \text { initial } \\ m & \text { mainstream } \\ s & \text { smooth wall } \\ t & \text { total } \\ w & \text { wall }\end{array}$

\section{REFERENCES}

Chyu, M. K. (1990) Heat Transfer and Pressure Drop for Short Pin-Fin Arrays with Pin-Endwall Fillet, Trans. ASME, Journal of Heat Transfer, 112, 926-932.

Chyu, M. K., Hsing, Y. C. and Natarajan, V. (1998) Convective Heat Transfer of Cubic Fin Arrays in a Narrow Channel, Trans. ASME, Journal of Turbomachinery, 120, 362-367.
Chyu, M. K., Hsing, Y. C., Shih, T. I. P. and Natarajan, V. (1999) Heat Transfer Contributions of Pins and Endwall in Pin-Fin Arrays: Effects of Thermal Boundary Condition Modeling, Trans. ASME, Journal of Turbomachinery, 121, 257-263.

Dittus, F. W. and Boelter, L. M. K. (1930) University of California at Berkeley, Publications in Engineering, 2, 443.

Hwang, J. J., Lai, D. Y. and Tsia, Y. P. (1999) Heat Transfer and Pressure Drop in Pin-Fin Trapezoidal Ducts, Trans. ASME, Journal of Turbomachinery, 121, 264-272.

Hwang, J. J. and Chen, C. S. (1999) Augmented Heat Transfer in a Triangular Duct by Using Multiple Swirling Jets, Trans. ASME, Journal of Heat Transfer, 121, 683-690.

Kline, S. J. and McClintock, F. A. (1953) Describing Uncertainties on Single-Sample Experiments, Mechanical Engineering, 75, 3-8.

Lau, S. C., Kim, Y. S. and Han, J. C. (1987) Local Endwall Heat/Mass Transfer Distributions in Pin Fin Channels AIAA, Journal of Thermophysics and Heat Transfer, 1, 365-372.

Lau, S. C., Han, J. C. and Kim, Y. S. (1989) Turbulent Heat Transfer and Friction in Pin Fin Channels with Lateral Flow Injection, Trans. ASME, Journal of Heat Transfer, 111, 51-58.

Metzger, D. E., Berry, R. A. and Bronson, J. P. (1982) Developing Heat Transfer in Rectangular Ducts with Staggered Pin Fins, Trans ASME, Journal of Heat Transfer, 104, 700-706.

Metzger, D. E., Fan, C. S. and Haley, S. W. (1984) Effects of Pin Shape and Array Orientation on Heat Transfer and Pressure Loss in Pin Fin Arrays, Trans ASME, Journal of Heat Transfer, 106, $252-257$.

VanFossen, G. J. (1982) Heat-Transfer Coefficients for Staggered Arrays of Short Pin Fins, Trans ASME, Journal of Heat Transfer, 104, $268-274$. 

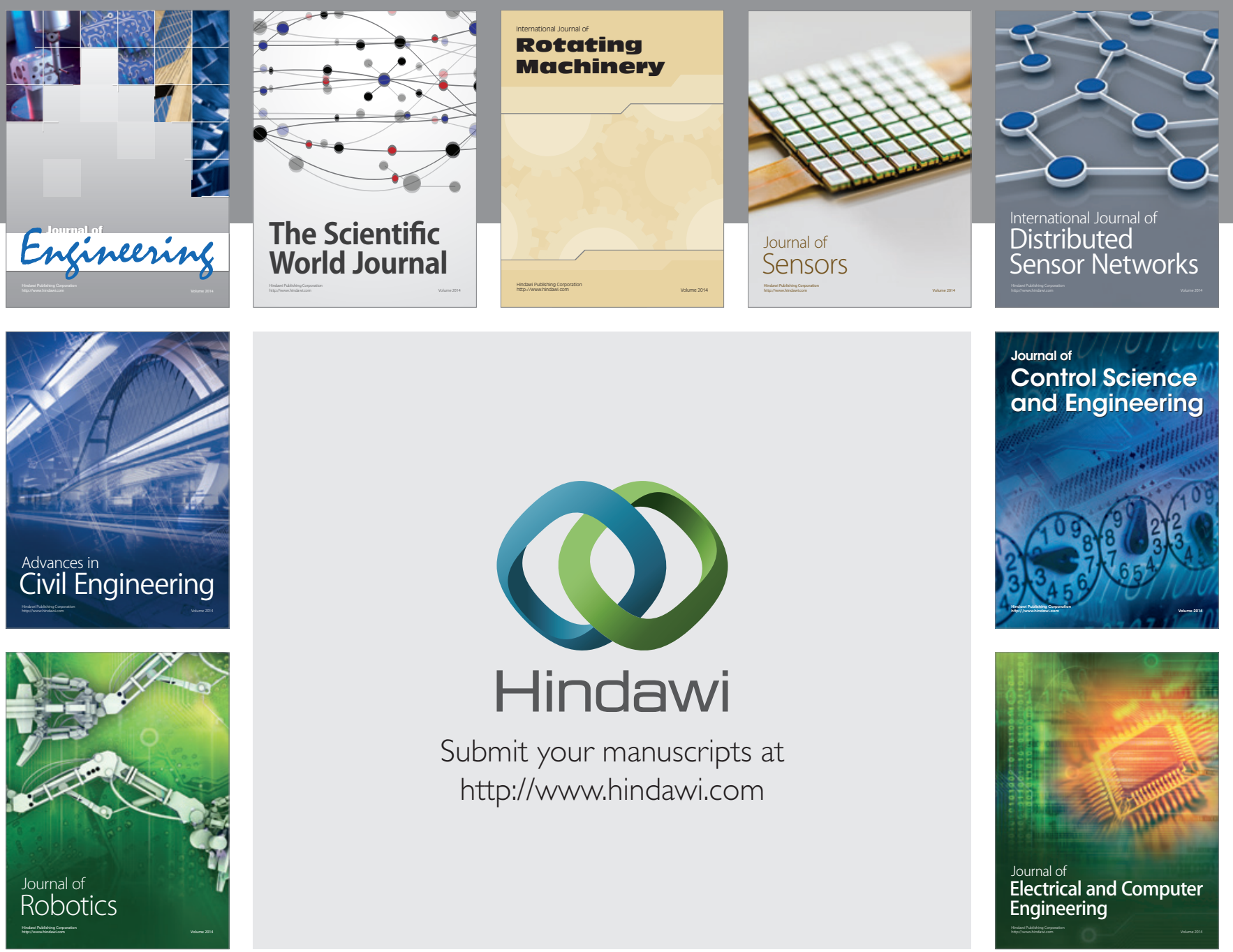

Submit your manuscripts at

http://www.hindawi.com
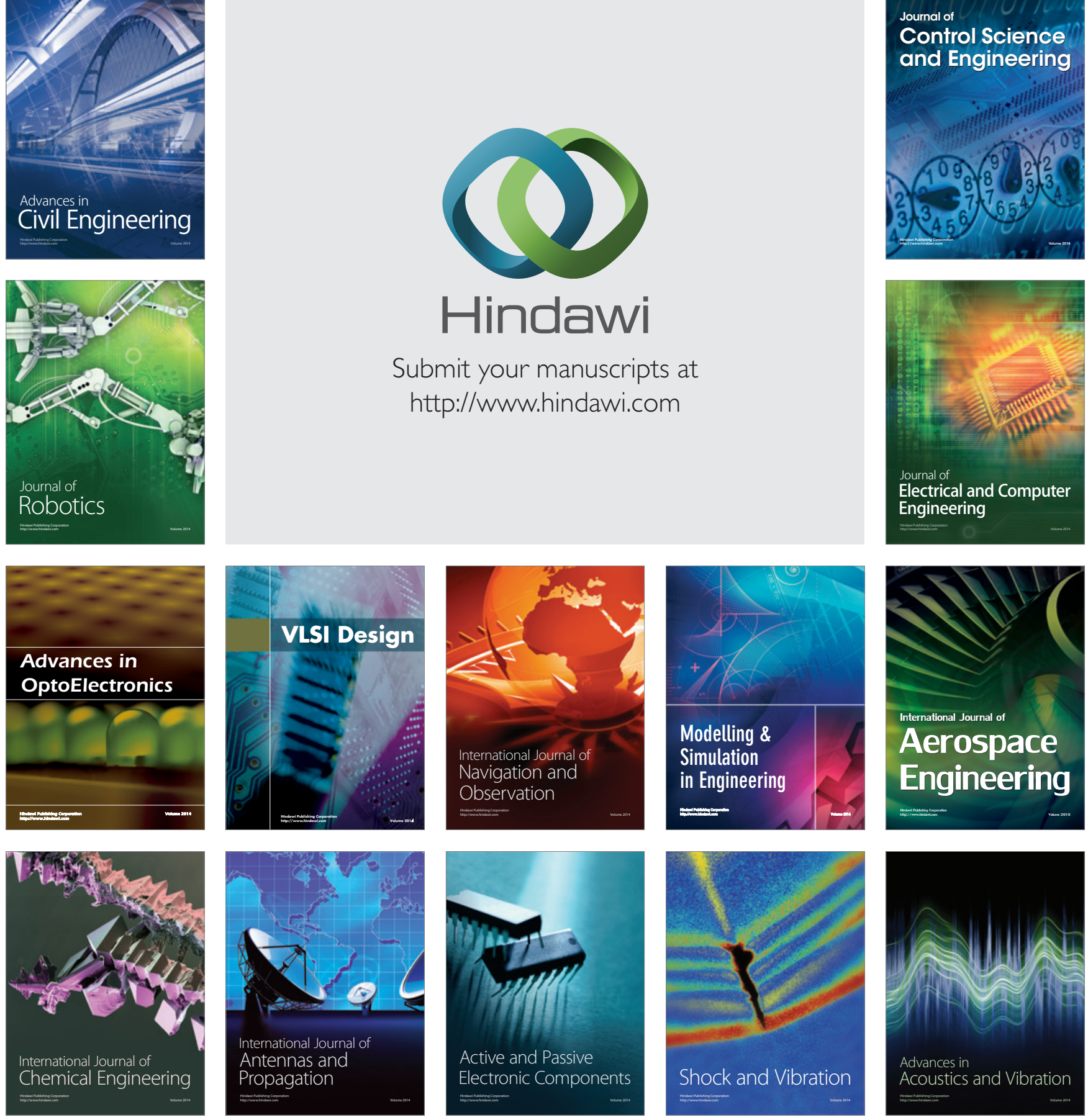